\title{
La estabilidad de los planes urbanísticos
}

El Consejero de Estado italiano Virgilio Testa, en su notable y moderno Manual de Legislación Urbanistica (Milano, 1956), al concretar las caracteristicas juridico-administrativas de los planes urbanisticos, las reduce a tres: obligatoriedad, publicidad y estabilidad.

La aplicación rigurosa del plan nace de su carácter legal y de st: interés general; es consecuencia de la igualdad de todos ante la l€y y viene exigida por la injusticia que supone la excepción no reglada.

La publicidad, sinónima de colaboración, tan necesaria para facilitar la ejecución de los planes, es vista con poca simpatia por la Administración en sus tres fases de elaboración, aprobación y ejecutoriedad de los planes; en el primer periodo recela de sus propios integrantes y teme a la oposición de los intereses afectados; en el segundo se limita a cumplir, generalmente de mal grado, la exigencia legal de la información pública, y en el tercero, sin más que publicar el acuerdo y a veces aún antes, procede a su ejecución. Ello $\epsilon \varsigma$ debido a que se olvida que los planes generales tienen por fin la ordenación, no la Ordenanza; ésta se impone, aquélla ha de ser fruto de una colaboración de los intereses afectados por el nuevo orden que sé quiere establecer. Porque, como vamos a ver, los planes urbanísticos no tienen, en muchos casos, por fin ordenar, siro reordenar.

De ahí, sin duda, que Virgilio Testa añada a las características de cbligatoriedad y publicidad de los planes urbanísticos la estabilidad, la que, traduciéndole a la letra, la entiende wen el sentido que los planes urbanísticos pueden ser modificados sólo cuando exigencias públicas de notable importancia $\mathrm{y}$ diligentemente atinadas lo reclamen), y añade: (como es obvio, la eventual variante podrá ser adoptada sometiéndose a las observancias de procedimiento establecidas para la formación de los planes originales).

No puede negarse que las reservas sobre variaciones de los planes anteriores no pueden ser mayores. 
Por ello, sin duda, habrá dicho más arriba, al tratar del urbanismo. en general, que no debe olvidarse ula tendencia de los organismosiocales a resolver unilateralmente el problema urbanistico» y que "cualçuier forma de egoísmo y de particularismo es despreciable en el funcionamiento de la Administración públicay.

La aplicación de la moderna Ley del suelo y ordenación urbana ha. venido a actualizar, en nuestra Patria, estas materias, pues a pretexto de la generalidad de su ámbito se ha olvidado con frecuencia que desdehace un siglo, y elaborados con arreglo a técnicas modernas, vienen 1 igiendo planes urbanísticos en la mayoria de las poblaciones importantes de España, y que la primera y fundamental misión de la Ley es tratar de urbanizar, con renovadas técnicas, nuevos espacios para. facilitar solares aptos y accesibles a la iniciativa privada para su edifícación.

Esta labor es de desear sea proyectada sobre zonas vírgenes urba-nisticamente, o en su defecto en zonas que tuvieran ya su plan aprobado, aunque no ejecutado; en cuyo caso, como decíamos con Testa, por tal exigencia pública de notable importancia podrá modificarseel plan con soluciones "diligentemente atinadas» y las consecuencias, económicas que ello comporte, que no pueden ser las mismas que si: se tratara de una zona rústica.

Más allá de estas dos zonas, la rústica y la que aún sin urbanizar totalmente se hallare ya afectada a planes urbanísticos aprobados con: anterioridad a la Ley, aparece el casco de la población, para cuya alteración son necesarias razones más poderosas $y$, sobre todo, soluciones mucho más diligentemente acertadas.

Asi lo ha entendido sin duda nuestra Ley, al separar de la calificación del plan parcial (arts. 10 y 11) los proyectos de reforma interior $y$ aun los de extensión, tratados específicamente en el articulo 12, y sobre los que nada dispone el siguiente capitulo II, por lo que quedan sometidos a la competencia municipal, sin perjuicio de que en caso de revisión se atengan a la zonificación que hubiere podido prever, para cada casco urbano, los planes nacionales, provinciales 0 . comarcales, bajo cuya jurisdicción se encuentre el término municipal.

El artículo 37 , con ánimo sin duda de reconocer como caracteristica de los planes urbanísticos la estabilidad, limița su revisión a los quince años, cuyo texto, por tanto, no debe ser interpretado. como imperativo, sino como un límite a la facultad revisora. 
El plazo de cinco años señalado a los Ayuntamientos por el articulo 38 siguiente, nada tiene que ver con aquella facultad, pues se refiere al programa de actuación, o sea, al ritmo de ejecución de los planes parciales, tanto por la claridad de su texto, como porque ya es sabido que a los Ayuntamientos se les niega competercia para revisar toda clase de planes.

La estabilidad, por tanto, es querida por nuestra Ley y debe ser respetada en general beneficio y en mutuo interés de administradores y administrados.

No tenemos una gran seguridad en que nuestro punto de vista sea compartido por algunos urbanistas, sobre todo por los pocos que creen más factible variar lo existente que crear lo nuevo, pero sin duda tales discrepancias favorecen la acomodación de lo existente a las exigencias modernas $y$, sobre todo, el lograrlo con menor daño $y$, aún alguna vez, con menor coste.

En lo que sí esperamos estar de acuerdo, con todos los urbanistas, es en que sus proyectos actuales perduren más allá de los quince años en que la Ley autoriza su revisión, pues sólo con la estabilidad de los planes pueden alcanzarse los fines que en su concepción se persiguieron.

ENrique de JANer y DURÁn

Secretario de $\mathrm{I}^{2}$. Categoria de Administración Local 